\title{
Office of Fair Trading $v$ Abbey National plc and others: Fifteen All in the Game between the Office of Fair Trading and the Banks
}

\section{$\underline{\text { Abstract }}$}

The subject of bank charges has excited considerable press coverage, and some campaigning by consumer groups. Complaints have multiplied, and litigation at the County Court level has increased to worrying levels. Under the Unfair Terms in Consumer Contracts Regulations 1999 the Office of Fair Trading can consider whether terms in consumer contracts are unfair. The OFT have commenced an investigation into bank charges under the Regulations. In Office of Fair Trading $v$ Abbey National plc and others the High Court was asked two questions: whether the contractual terms that imposed bank charges were liable to an assessment for unfairness under the Regulations; and whether the same terms constituted penalty clauses under the common law. The judge ruled in favour of the banks that the clauses were not penalty clauses, and in favour of the OFT that the contractual terms were liable to assessment for unfairness under the Regulations.

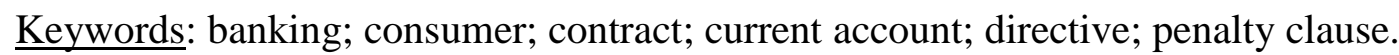

\section{$\underline{\text { Introduction }}$}

The legality of contemporary banking practices in levying bank charges on current account customers was the underlying issue in Office of Fair Trading $v$ Abbey 
National plc and others (OFT v Abbey) [2008] EWHC 875 (Comm); [2008] All ER (D) 349 (Apr) and [2008] EWHC 2325 (Comm) (Oct). The case was not concerned with all bank charges payable by customers. The relevant charges were those levied upon the receipt of payment instructions from customers when there are insufficient funds to meet the instructions; and the charges levied for an outstanding debit balance on a current account in excess of that agreed between the customer and the bank. Other charges, such as the charge made on a bank account subject to a standard monthly charge, were not challenged. The relevant charges seem to be universally levied on customers who have 'free' when in credit current accounts, or free when within a pre-arranged overdraft limit current accounts. Recently the levying of the relevant charges has been challenged, often successfully, by many customers. Downloadable complaint and claim forms are available on the internet, and it is has been reported that over one million have been downloaded. There have been large numbers of court actions commenced against banks, claiming repayment of the relevant charges, on the ground that they have been illegally levied. ${ }^{1}$

\footnotetext{
${ }^{1}$ For the claim that 1,000,000 forms have been downloaded: see Hilary Osborne and Jill Treanor, The Guardian, 23/5/08. On the history of the litigation by customers: see Stephen Gerlis DJ, Times Online, 7/6/07. On the substantial County Court litigation stayed pending resolution of the process initiated by the OFT: see David Prosser, The Independent, 23/5/08. On the extension of a waiver to banks, suspending their obligation to consider complaints by customers over the relevant charges, as granted by the Financial Services Authority: see Hilary Osborne and agencies, Guardian.co.uk, 21/7/08. All sources available online and last accessed 31/7/08. Some County Court judgments that were heard before the stay have been reported: see Berwick v Lloyds TSB Plc and Haughton v Lloyds TSB Plc heard on 15 May 2007 at the Birmingham County Court and Gillin v Lloyds TSB Plc heard on 26 June 2007 at Coventry County Court: each Court ruled against the customers on the grounds that the relevant charges were not penalties, as the charges were not levied on a breach; and that the UTCCR
} 
OFT v Abbey was commenced by the Office of Fair Trading (OFT) pursuant to a duty imposed upon it by the Unfair Terms in Consumer Contracts Regulations 1999 (UTCCR) and a power granted it by the Enterprise Act 2002. As well as the Abbey National plc six other clearing banks and the Nationwide Building Society were party to the litigation. The litigation was undertaken pursuant to Litigation Agreements between the parties and the Financial Services Authority. It is effectively a test case, and has already been appealed by the defendants. ${ }^{2}$

Two legal issues were raised in OFT v Abbey. The first issue was the possible application of the UTCCR to those contractual terms that imposed the relevant charges. The second issue was the possible application of the common law against penalties to those same terms. With respect to UTCCR the hearing was concerned with preliminary issues: essentially, whether the contractual provisions were subject to review for unfairness under the UTCCR. Andrew Smith J held that the relevant terms were liable to be assessed for unfairness against the standard contained in the Regulations. However, he heard no argument, and made no ruling, on the question of whether the provisions were 'unfair'. He ruled that the law of penalties did not apply to the provisions.

\footnotetext{
did not operate because reg 6(2)(b) applied to exclude the term imposing the charges from the operation of reg 5 .

${ }^{2}$ For the powers and duties of the OFT see: regs 10 and 12 UTCCR 1999, SI 1999/2083 and ss. 213(1) \& 215(2) Enterprise Act 2002. The six other clearing banks were: Barclays Bank plc, Clydesdale Bank plc, HBOS plc, HSBC Bank plc, Lloyds TSB Bank plc, and the Royal Bank of Scotland Group plc (which includes National Westminster Bank plc and Royal Bank of Scotland plc).
} 
Subsequent to the decision in OFT $v$ Abbey the OFT has published a market study under section 5 of the Enterprise Act: 'personal current accounts in the UK'. The report will inform the investigation under the UTCCR. The report was critical of the current situation in the industry. The OFT has not yet made public its deliberations over whether the terms imposing the relevant charges are unfair under the UTCCR.

This note will consider the reasoning of the judge with respect to the law of penalties, then give a brief introduction to the UTCCR, and finally consider the application of the UTCCR to the relevant provisions. The case is of general interest from the perspectives of the law of banking, general contract law, and the law of consumer contracts. Further, due to the origins of the UTCCR, the case is of interest as an example of the application of a European Directive in the UK, and, arguably, as a crucial stage in the harmonization of contract law across the European Union.

\section{The common law prohibition of penalties}

On a preliminary matter, the propriety of the counterclaim brought by the defendants that the relevant terms were not penalties is doubtful. The desirability of a test case on the issue is plain. However, as the court ruled in relation to a request for a declaration on the meaning of 'good faith' in the UTCCR, it is not appropriate for the Courts to make rulings 'in the abstract and without reference to specific facts'. An inherent limitation of $O F T v$ Abbey is that the terms and conditions of business customers were not considered, as the UTCCR are concerned solely with consumer contracts. ${ }^{3}$

\footnotetext{
${ }^{3}$ [2008] EWHC 875 (Comm) paras 5 to 9; 36; 75 and 76; and 440 to 447 . The quote is from para 440.
} 
This problem was expressly addressed by Andrew Smith $\mathrm{J}$ in a subsequent judgment delivered in October that considered whether older standard terms of the banks were capable of being penalty clauses. ${ }^{4}$ He decided it was appropriate to make declarations in the absence of any customers as parties, and in part upon the basis of admissions and concessions make by the OFT. Three factors influenced the judge's reasoning. The issue concerned the construction of standard form contractual provisions, and the judge did not consider that any relevant facts were not before the court. The case was brought in part as a test case, in order to manage the significant numbers of cases brought by customers, and the declarations would be crucial for this purpose. Finally, the OFT had acted in the litigation in the role of representative bank customer. Furthermore, both the judge and counsel for the FSA felt that the admissions and concessions made by the OFT were appropriate. ${ }^{5}$

The jurisdiction of the courts to strike down a 'penalty' in a contract was already well established in 1914, when the House of Lords decided Dunlop Pneumatic Tyre Co Ltd v New Garage and Motor Co Ltd [1915] AC 79. In brief, the law will uphold a contractual provision that provides for the payment by a party in breach of contract that is a true pre-estimate of the damages likely to follow from that type of breach. However, the law will not enforce a provision that imposes a punitive payment to be made in the event of a breach of contract, the threat of which can be held over a party to the contract like a sword of Damocles to enforce compliance with the contractual obligations of that party. Usually, in litigation over the classification of a clause as a penalty or not, the issue in dispute is whether the clause represents a true pre-estimate of damage caused by the type of breach that is suffered by the party trying to enforce

\footnotetext{
${ }^{4}$ [2008] EWHC 2325 (Comm).

5 [2008] EWHC 2325 (Comm) at paras 4-7. When the OFT did argue that further facts were necessary to resolve a point of construction the argument was rejected by the judge: para 33 .
} 
the provision. In $O F T v$ Abbey there was no attempt by the defendants to show that the relevant provisions represented a true pre-estimate of damage. The defence was at a more fundamental level. It was argued that the relevant charges were not made upon any breach of contract at all, and, therefore, could not possibly be penalties imposed upon a breach of contract. The validity of this argument depended upon an analysis of the contract that governed the relationship between the bank and its customer. ${ }^{6}$

Andrew Smith J dealt with the nature of the banker customer contract, and what actions or omissions constitute a breach thereof, towards the beginning of his judgment. He relied heavily upon the analysis of the contractual situation that arises from the receipt by a bank of a payment instruction from its customer by Goff $\mathrm{J}$ in Barclays Bank Ltd v W J Simms Son \& Cooke (Southern) Ltd [1980] 1 QB 677. This case is more familiar for its authoritative analysis of the type of mistake that will ground recovery for unjust enrichment following a mistaken payment. In the words of the judge: 'Prima facie a customer is not in breach of his contract with his bank if he gives instructions to make a payment without having the necessary funds or facility to cover the payment'. This conclusion follows from the fact that a bank is not obliged to honour a payment instruction in the absence of available funds, or an agreed overdraft. Therefore, the issuing of the instruction has no adverse effect upon the bank. Specifically, it does not put it at risk by forcing a loan from it. Any payment in compliance with the payment instruction is made voluntarily by the bank, and cannot realistically be viewed as a breach by the customer of its contractual obligations. Thus, charges made upon the honouring of payment instructions are not charges imposed upon a breach of contract by the customer, but rather charges imposed upon

\footnotetext{
${ }^{6}$ Ibid para 296.
} 
a voluntary decision by the bank to make the relevant payment despite it being "unauthorised". Unauthorised importing not authorised in advance as an agreement to extend overdraft facilities. $^{7}$

Whilst not strictly speaking determinative of whether the charges were penalties this analysis effectively decided the issue. Theoretically, the defendant's standard terms could impose contractual obligations on the customer that would make the issuing of payment instruction in the absence of funds a breach of contract. However, this was unlikely, especially with respect to the more recent terms, deliberately drafted to suggest the charges are not penalties. The analysis of the current account and payment instructions laid the foundation for the subsequent reasoning, and for the conclusion in April that all of the relevant contractual provisions he could make a decision about were incapable of being penalties.

The imposition of a charge upon the use of a cheque guarantee card to make a payment in absence of funds falls outside of this reasoning. The bank does not have a free choice of whether to honour the cheque, as it incurs an obligation to pay owed to the payee of the cheque. This entailed a particularly close consideration of any standard terms and conditions that imposed a charge for use of a cheque guarantee card in the absence of adequate funds in the customer's account to meet the payment. ${ }^{8}$ The issue was easier to resolve, in favour of the bank, if any charge was levied whenever a payment instruction was honoured, or whenever an overdraft arose or increased because a payment instruction was honoured, regardless of whether a

\footnotetext{
${ }^{7}$ Ibid paras 42 to 82 ; and 295 to 331 : the quote is from para 64 . The judge quoted the same passage in [2008] EWHC 2325 (Comm) at para 9.

${ }^{8}$ [2008] EWHC 875 (Comm) at para 66 and [2008] EWHC 2325 (Comm) at paras 16-20. The same logic applies to the use of a debit card for a payment below a merchant's "floor limit", as noted: [2008] EWHC 875 (Comm) at para 49.
} 
guaranteed payment instruction was involved. ${ }^{9}$ It was charges levied on misuse of cheque guarantee cards that formed the focus of the arguments by the OFT considered in the October judgment. In its arguments directed to the older standard banking terms and conditions the OFT tried to accommodate the analysis of the customer and banker contract adopted by the judge in his April judgment. It argued that the relevant terms made it a breach to issue a payment instruction, rather than a breach occurring upon any subsequent honouring of the instruction. This did have the effect of avoiding the argument that there was unlikely to be any breach by the customer when the bank decided to honour a payment instruction. However, it also entailed a very strained and unnatural construction of the standard terms under review, which referred to charges being levied upon payments being made, or overdrafts granted in order to honour payment instructions. In his October judgement the judge held that most of the terms and conditions under review could not be penalty clauses, as they did not impose a charge upon a breach of contract by the customer. For most of the defendants the judge was willing to declare that their bank chares were not capable of being penalties at common law. However, further submission were invited with respect to the standard terms of Lloyds TSB (largely because the bank had not had full written terms and conditions for its current account customers) and of the Royal Bank of Scotland Group's member the NatWest. Andrew Smith J considered that the NatWest terms might have been capable of being penal, but he was unwilling to make a final decision. Possibly, his reticence was encouraged by the need for further evidence in relation to a leaflet issued by NatWest that also seemed to border on being capable of being penal. ${ }^{10}$

\footnotetext{
${ }^{9}$ [2008] EWHC 875 (Comm) at paras 308-312; [2008] EWHC 2325 (Comm) at para 32.

${ }^{10}[2008]$ EWHC $2325(\mathrm{Comm})$ at paras 120-130.
} 
Two further questions are raised by the argument that the relevant bank charges were not imposed upon any breach of contract. First, is the legitimacy of the use of freedom of contract to determine what actions constitute a breach of that contract, given the mandatory and protective nature of the law against penalties. It is well established that the mere designation of a clause as a pre-estimate of damages, or indeed as a penalty, is not conclusive. The judge dealt with this issue immediately after his analysis of the current account. Given his conclusions on the contractual situation that obtains when a customer gives a payment instruction he unsurprisingly found references to 'requests for an overdraft', and 'informal overdrafts', or 'unplanned borrowing', to be expressions that reflected the true legal effects of the issuing of payment instructions by a customer in the absence of available funds or loan facilities for making the payment. ${ }^{11}$

Second, is how accommodating or how restrictive the courts should be towards claims that contractual provisions are penalties. The judge did not explore this issue expressly. His reasoning was certainly in harmony with the most authoritative dicta on this issue. The classic statement of the generally restrictive approach that is apposite was made by Diplock LJ in Philip Bernstein (Successors) Ltd v Lydiate Textiles Ltd (1962) unreported, transcript no. 238 of 1962, CA:

I, for my part, am not prepared to extend the law by relieving against an obligation in a contract entered into between two parties which does not fall within the well defined limits in which the court has in the past shown itself willing to interfere.

\footnotetext{
${ }^{11}$ Ibid paras 67 to $76 ; 105,106,137$, and 207; and 338.
} 
This statement was adopted by Lord Roskill in Export Credits guarantee Department v Universal Oil Products Co [1983] 1 WLR 399 at 404. The reasoning of Andrew Smith J was also consonant with a dictum of Millett LJ in Jervis v Harris [1996] Ch 195 at pp 206-207. Millett LJ opined that restraint is particularly apposite when: 'the court is asked for the first time to strike down a standard clause which has been familiar to property lawyers for generations'. Finally, it should be noted that the UTCCR offer a new and powerful tool for the judicial control of standard form consumer contracts. It seems almost perverse to extend the law of penalties in this field at the very time that contractual freedom has been constrained by these far reaching Regulations, unless a clear policy failure in the UTCCR requires an active intervention by the common law. ${ }^{12}$

\section{The UTCCR}

The UTCCR were promulgated in response to the Council Directive on Unfair Terms in Consumer Contracts (EEC) 93/13, and replaced earlier Regulations promulgated in 1994. The Regulations provide that the terms of standard form consumer contracts for the provision of goods or services are subject to a standard of 'fairness' laid down by Regulation 5. Any term that falls short of the requisite standard does not bind a consumer, and can be the subject of an enforcement order prohibiting its use. The OFT is the leading enforcement body of the Regulations, with the duty to make assessments of fairness, and able to apply for enforcement orders prohibiting the use of an unfair term. Regulation 6 excludes from assessment under Regulation 5 those contractual terms that deal with the adequacy of consideration in a contract, provided

\footnotetext{
${ }^{12}$ Ibid see: paras 328 to 331.
} 
the relevant terms are in 'plain intelligible language'. The requirement of comprehensible written terms is also relevant for Regulation 7, which imposes a contra proferentem construction on offending written terms. Regulation 7 has this effect in the context of litigation between consumer and supplier, but not in disputes between an enforcer and a supplier. ${ }^{13}$

The defendants argued that the relevant terms were not subject to assessment for fairness under Regulation 5, because they were excluded from such assessment by Regulation 6. The defendants argued that their terms were in plain and intelligible language, and that the relevant charges were an integral part of the price paid for use of current account services, and as such within the Regulation 6 exception.

Therefore, OFT v Abbey was not concerned with the application of Regulation 5 to the relevant terms. The OFT intends to make such an assessment in the future. The case was concerned with the applicability of the Regulation 6 exception to the relevant terms. Regulation 6 provides:

Assessment of unfair terms

(1) $\ldots$

(2) In so far as it is in plain intelligible language, the assessment of fairness of a term shall not relate-

(a) to the definition of the main subject matter of the contract, or

\footnotetext{
${ }^{13}$ The earlier Regulations were the Unfair Terms in Consumer Contracts Regulations 1994, SI 1994 No. 3159. See: regs 3, 5(2), 8, 10, and 12 of the UTCCR. See: Enterprise Act 2002, Part 8. Note: reg 7 can apply to individually negotiated terms whereas regs 5 and 6 do not.
} 
(b) to the adequacy of the price or remuneration, as against the goods or services supplied in exchange.

The decision confirmed the liability of the relevant contractual terms to assessment under Regulation 5 by the OFT. The crucial provision for this decision was regulation 6(2)(b), which was given a narrow construction by the judge who rejected the argument that the relevant charges should be considered to be the price of the services provided by banks to their current account customers, and therefore within the terms of $6(2)(b)$.

\section{Application of Regulation 6(2) CTCCR in OFT v Abbey}

The consideration of what was demanded by the requirement that a 'term' be in 'plain intelligible language' was of interest in several ways. The person who should be able to find the term intelligible is the 'typical' or 'average' customer, who is no doubt a close relation of the reasonable man. It was held that the requirement applies solely to express terms, and not to implied terms. It was held that the requirement does not extend beyond the intelligibility of the words used, so that the UTCCR do not impose a duty to ensure that a consumer understands fully the effects of a contract. The word 'term' is not synonymous with 'clause', and a term might be expressed in different places in a standard form; which in itself might create problems of intelligibility. In a similar manner non-contractual documentation might be relevant to the question of whether a term was in plain and intelligible language, if the non-contractual documents might cause confusion. So, documentation that is not of contractual effect is not subject to the requirement that it be in plain and intelligible language. However, 
if it is confused or unintelligible then extra contractual material might render the contractual language less intelligible. Unfortunately, some explanations make it harder to understand the thing explained. Finally, the requirement is that the terms be expressed in plain intelligible language, not that a good attempt has been made to so express them. ${ }^{14}$

A large section of the judgement was taken up with a consideration of the standard form documents, contractual and non-contractual in effect, given out by the banks to their customers, connected with the imposition of the relevant bank charges. It was concluded that most of the terms were expressed in a manner that was plain and intelligible, with minor exceptions. Therefore, the judgment proceeded to consider whether the terms were within the words of Regulation $6(2)(b) .{ }^{15}$

The construction of Regulation 6(2)(b) was informed by the Directive on Unfair Terms in Consumer Contracts; the decision of the House of Lords in Director General of Fair Trading v First National Bank Plc [2002] 1 AC 481 (DGFT v First National), which construed the equivalent provision in the 1994 Regulations; and by the change in the heading of Regulation 6 between the two versions of the Regulations. A construction that read paragraphs 6(2)(a) and 6(2)(b) as implicitly tied together; so that $6(2)(\mathrm{b})$ was limited to the price or remuneration for the main subject matter of the contract; was rejected as not supportable on the wording of the Regulation, or the Directive. However, it was held, following DGFT v First National, that a restrictive construction had to be given to Regulation 6(2)(b), in order to not

\footnotetext{
${ }^{14}$ [2008] EWHC 875 (Comm) paras 89 to 93; and 100 to 121.

${ }^{15}$ Ibid paras 130 to 293.
} 
frustrate the consumer protective purpose of the Directive and Regulations. The words 'price or remuneration' in Regulation 6(2)(b) were intended to indicate that which was given in exchange for the goods or services provided by the supplier under the contract. Not all payments due from the consumer under the contract would fall within the ambit of these words. In an attempt to formulate a test to distinguish between payments within or outside the exception the judge put forward: "the question whether typical parties to a transaction of the kind under consideration would recognise a payment as the price or remuneration is a useful guide as to whether a payment falls within the Regulation'. This attempt at an objective (in the sense of the word usual in contract law) approach to what constitutes the 'price or remuneration' is consonant with the approach taken to what constitutes 'plain intelligible language' in the context of the Regulation. ${ }^{16}$ This objective approach has some limited support in the speeches in DGFT v First National. ${ }^{17}$

In order to decide whether a payment is the price or remuneration for services provided it is necessary to identify the services being provided. In the context of $O F T$ $v$ Abbey these services could be either: all the services associated with a current account (deposit, payment systems, lending facilities etc); or, the relevant services might be the action by the bank upon which a charge is levied (receipt of payment instruction in absence of funds and payment thereof, loan of sufficient funds to honour payment etc). With respect to the events that triggered a charge it was held

\footnotetext{
${ }^{16}$ Ibid paras 344 to 350 ; and 384 to 390 . The quote is from para 388 .

${ }^{17}$ [2002] 1 AC 481 para 20 per Lord Bingham, but his remarks only supportive in a very weak sense, and are concerned with fairness rather than price or remuneration; and para 33 per Lord Steyn whose remarks are more clearly supportive, but again concerned with fairness.
} 
that banks do provide a service when they honour a payment instruction and extend credit to a customer, and do not provide a service when they refuse to honour a payment instruction. ${ }^{18}$ The defendants argued, in the alternative, that the charges under consideration were within the words of Regulation 6(2)(b): because the charges were the price for the package of services provided to the holder of a current account; and, because each charge was the price of the service provided when it was charged.

The first argument, that the charges were the price of the current account was rejected. It was held to be an unnatural use of language to describe the charges as the price charged for the current account. Further, even if it was accepted that the charges were charged as remuneration for supplying the services associated with a current account the argument demonstrated that the charges were part of the price only. The second argument that each charge was the price of a service supplied when it was levied was also rejected. Refusal to honour a payment instruction was not the provision of any service for which the charge could be the price. The honouring of payment instructions was not generally subject to any charge, unless funds were unavailable. In reality it was this circumstance that triggered the charge, not the service provided but the circumstances in which it was provided. There was no relationship between the levels of the charges imposed for honouring payment instructions, and lending the funds required to do so, and the costs to the banks or value to the customer, of the services provided. Finally, as with the first argument, if the charges were for services provided they were only part of the price for the same. In addition to these points relating to the reality of the contractual relations, two further factors influenced the decision. The charges were not presented to customers as the price of the current

\footnotetext{
${ }^{18}$ [2008] EWHC 875 (Comm) paras 359-383.
} 
account, and the charges would not be naturally recognised as such by a typical consumer when opening a current account. ${ }^{19}$

This decision, that Regulation 6(2)(b) does not apply to bank charges, as they are not the price or remuneration for relevant banking services was a serious blow for the defendants. It means that the terms that impose the relevant charges in the contracts of banks with their customers are vulnerable to review by the OFT for fairness under Regulation 5.

One final issue of general concern was considered in the course of the judgment, although it was not the subject of any holding. If Regulation 6(2)(b) had applied to the relevant contractual terms then the effect of that application would have fallen for consideration. There are two possible effects. First, that the term concerned simply cannot be subject to Regulation 5 assessment for unfairness. Second, that the term cannot be assessed for 'adequacy' of price or remuneration, but that it can be assessed for fairness in other ways. In favour of the second interpretation is the change to the heading of Regulation 4 in the 1994 Regulations and Regulation 6 of the 1999 Regulations. Regulation 4 of the 1994 Regulations was headed 'Terms to which these Regulations apply'. Regulation 6 of the UTCCR is headed: 'Assessment of unfair terms' ${ }^{20}$ The second interpretation is consonant with the parent Directive. The second construction avoids problems that might arise if the relevant 'term' is spread over several clauses of a contract. Finally, it gives effect to the word 'adequacy' in

\footnotetext{
${ }^{19}$ Ibid paras 398 to 414 .

${ }^{20}$ As noted by Chitty, Law of Contract (2004) $29^{\text {th }}$ ed at $15-034$ cited by Andrew Smith J at paras 422 and 429
} 
Regulation 6(2)(b), as if the term is excluded altogether whenever Regulation 6(2)(b) applies then it is difficult to see what the word 'adequacy' adds to the provision. ${ }^{21}$ In favour of the first interpretation are dicta in DGFT v First National, ${ }^{22}$ although the House did not hear argument on the issue, and was construing the 1994 Regulations. $^{23}$ Of more concern is the difficulty in applying the test imposed by the second construction, especially when a restrictive approach has already been taken as to which terms fall within the exception in the first place. It is unlikely that a term that falls within Regulation 6(2)(b) will contain much other than provisions that are concerned with the value of the price or remuneration contracted for by the supplier. The judge concluded that the preferred construction is the second, restricting the operation of Regulation 5 to the relevant term, rather than excluding the term totally from assessment for unfairness. ${ }^{24}$

Graham Ferris*

\footnotetext{
${ }^{21}$ [2008] EWHC 875 (Comm) paras 424 to 428; and 43.

22 [2002] 1 AC 481 paras 12, 34, and 435.

${ }^{23}$ [2008] EWHC 875 (Comm) para 430.

${ }^{24}$ Ibid. para 436.

${ }^{*}$ Senior Lecturer in Law, Nottingham Law School, Nottingham Trent University.
} 